\title{
Complications associated with labial salivary gland biopsy in the investigation of connective tissue disorders
}

\author{
A Richards, S Mutlu, C Scully, P Maddison
}

Parotid gland biopsy has been advocated in preference to labial gland biopsy in the investigation of Sjögren's syndrome on the grounds that the organ affected in the disease process should be the choice for biopsy. ${ }^{1}$ A technique for biopsying the parotid gland has been described and said to carry a low risk of fistula formation or damage to important anatomical structures. ${ }^{1}$ Biopsy of the palatal minor salivary glands has also been described in the investigation of Sjögren's syndrome, other connective tissue diseases, and sarcoidosis ${ }^{2-6}$ but can result in pain and occasional haemorrhage. Biopsy of the minor salivary glands of the lower lip has therefore now been used for many years as the histological changes there appear to correlate with those in the parotid and submandibular glands $^{7-9}$ and it is a relatively minor and safe procedure. More recently, reservations have been expressed about the specificity of labial gland biopsies ${ }^{1011}$ as lymphocytic foci have been demonstrated in other autoimmune disease, age dependent focal sialadenitis has been demonstrated in normal subjects, ${ }^{12}{ }^{13}$ and labial gland biopsy has been found occasionally to be negative in Sjögren's syndrome. ${ }^{14}$ Labial salivary gland biopsy is not totally atraumatic and patients seen by us, having had biopsies at our centre or others, have sometimes disliked the postoperative sequelae. Further, attention was drawn by one of our patients to lip numbness after biopsy, though the risk of damage to branches of the mental nerve supplying sensation to the lower lip should be negligible as the procedure requires a single linear mucosal incision well away from the plane of the nerve.

This study, therefore, aimed at establishing the incidence of lower lip anaesthesia or other complications following labial gland biopsies carried out for investigation of Sjögren's syndrome.

\section{Patients and methods}

The notes of 58 patients ( 53 female, five male) attending the Bristol Dental Hospital and the Royal National Hospital for Rheumatic Diseases, Bath, and who had had labial gland biopsy within the previous two years, were examined. The patients ranged in age from 20 to 72 years. Forty three patients were available for interview and examination by one member of staff, who had also carried out 28 of the biopsies. The labial salivary gland biopsy technique that had been used in virtually all cases was a horizontal mucosal incision, under local analgesia with $2 \%$ lignocaine and 1 in 80000 adrenaline, excision of six to eight glands, and closure with one or two $3 / 0$ or $4 / 0$ black silk sutures. Sutures were removed at seven days. Patients were explicitly questioned as to sequelae after biopsy, specifically for pain, infection, or anaesthesia.

The notes of the 15 patients unavailable for recall were also scrutinised for evidence of sequelae after labial salivary gland biopsies.

\section{Results}

Two patients complained of reduced sensation after labial gland biopsy over an area of the ipsilateral lower lip about $1-1.5 \mathrm{~cm}$ diameter. In one case completely normal sensation returned within a few weeks. The other patient had reduced sensation when seen after a year but this caused her no difficulty or distress and there was no objective loss on neurological testing. No patient had pain, wound breakdown, or infection severe enough to require treatment with antimicrobial drugs, and there were no complaints of scarring of the area or other problems.

\section{Discussion}

The relative importance of the various investigative techniques used in the diagnosis of Sjögren's syndrome remains controversial despite the well accepted Copenhagen criteria. ${ }^{15} 16$ Investigations should ideally be minimally invasive with a low risk of serious complications or discomfort.

Labial gland biopsies are associated with some postoperative discomfort and swelling but, as shown in this series, the risk is clearly very small, probably less than $2 \%$. As the incision should be too superficial to cause nerve damage possibly the suturing and entrapment of nerve fibres might have been responsible for the minimal neuropathy in the two cases described. The procedure for labial gland biopsy may be more acceptable to patients than the prospect of a skin incision and possible complications from parotid biopsy. Biopsies of the palate may be painful and may be complicated by prolonged bleeding. $^{2}$

In summary, labial gland biopsies are mini- 
mally invasive, have a low complication rate, and are readily accepted by most patients and, as the specificity and sensitivity are still sufficient to diagnose most cases of Sjögren's syndrome, such biopsies are likely to remain the keystone to diagnosis for the foreseeable future.

1 Ferguson J W, Edwards J L, Christmas P I, Ferguson M M. Parotid gland biopsy for investigation of xerostomia. $\mathrm{Br} \mathfrak{J}$ Oral Maxillofac Surg 1990; 28: 234-7.

2 Eisenbud L, Platt N, Stern D M D, D'Angelo W, Sumner P. Palatal biopsy as a diagnostic aid in the study of connective tissue diseases. Oral Surg 1973; 35: 642-8.

3 Cahn L R, Eisenbud L, Blake M, Stern D. Biopsies of normal-appearing palates of patients with known sarcoidosis. Oral Surg 1964; 18: 342-5.

4 Cifarelli P, Bennett M, Zaino E. Sjögren's syndrome: a case with an additional diagnostic aid. Arch Intern Med 1966; 177: 429-31.

5 Cahn L R. A milder type (forme fruste) of Siögren's syndrome. Oral Surg 1967; 23: 25-8.

6 Abramson A, Goodman M, Kolodny H. Sjögren's syndrome: additional diagnostic tools. Arch Otolaryngol 1968; 88: 91-4

7 Wise C M, Agudelo C A, Semble E L, Stump T E, Woodruff
R D. Comparison of parotid and minor salivary gland biopsy specimens in the diagnosis of Siögren's syndrome. Arthritis Rheum 1988; 31: 662-6.

8 Bertram U, Hjorting-Hansen E. Punch biopsy of minor salivary glands in the diagnosis of Sjögren's syndrome. Scand F Dent Res 1970; 78: 295-300.

9 Chisholm D M, Waterhouse J P, Mason D K. Lymphocytic sialadenitis in major and minor glands: a correlation in post mortem subjects. F Clin Pathol 1970; 23: 690-4.

10 Hedfors E, Lindahl G. Studies on the specificity of the immunohistopathological changes of the salivary glands in Sjögren's syndrome. Clin Exp Rheumatol 1989; 7: 163-5.

11 Vitali C, Monti P, Giuggioli C, et al. Parotid sialography and lip biopsy in the evaluation of oral component in Siögren's syndrome. Clin Exp Rheumatol 1989; 7: 131-5.

12 Waterhouse J P. Focal adenitis in salivary and lacrimal glands. Proc Roy Society Med 1963; 56: 911-8.

13 Scott $J$. The incidence of focal chronic inflammatory changes in human submandibular salivary glands. F Oral Pathol 1976; 5: $334-46$

14 Katz J, Yamase H, Parke A. A case of Sjögren's syndrome with repeatedly negative findings on lip biopsy. Arthritis Rheum 1991; 34: 1325-8.

15 Prause J U, Manthorpe R, Oxholm P, Schiodt M. Definition and criteria for Sjögren's syndrome used by the contributors to the First International Seminar on Sjögren's syndrome to the First International Seminar on Sjögren's syndr
1986. Scand I R Reumatol [Suppl] 1986; 61: 17-18.

16 Manthorpe R, Oxholm P, Prause J U, Schiodt M. The Copenhagen criteria for Siögren's syndrome. Scand $f^{\prime}$ Rheumatol [Suppl] 1986; 61: 19-21. 